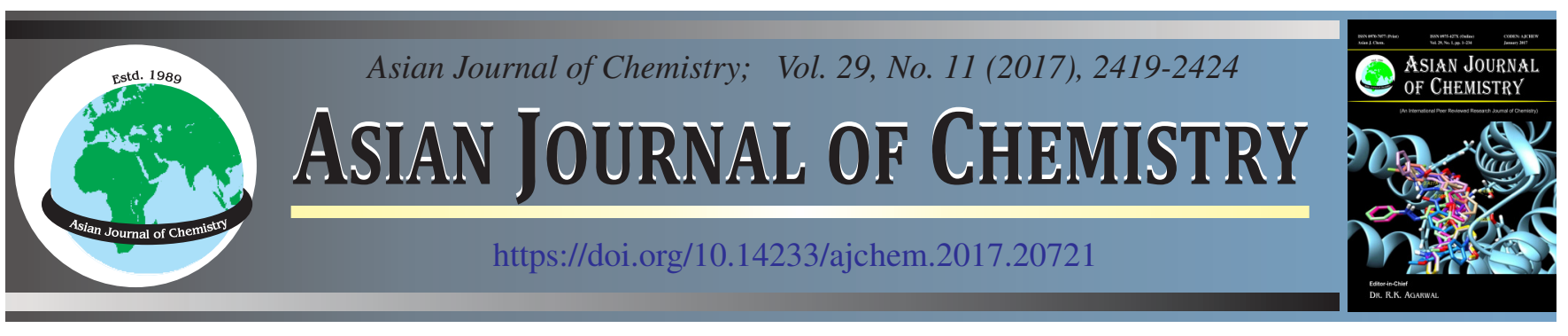

\title{
Ion-Exchange Applications of Newly Synthesized of Aminoacetophenone, Biuret, Formaldehyde Derivative as New Chelating Terpolymer Resin
}

\author{
Azhar Kamil Rashid* and Khalida Abbas Omran
}

Department of Chemistry, College of Education for Pure Science/Ibn Al-Haitham, University of Baghdad, Baghdad, Iraq

*Corresponding author: Tel: +964 7714794280; E-mail: azhar_almasody@yahoo.co.uk

A new chelating terpolymer resin $(o-\mathrm{AABF})$ was synthesized through copolymerization of $o$-amino acetophenone, biuret, formaldehyde in $(1: 1: 3)$ mol ratio in acidic medium $(\mathrm{HCl})$ by condensation reaction. The synthesized copolymer resin was characterized by UV-visible, FTIR and ${ }^{1} \mathrm{H}$ NMR techniques. The empirical structure and molecular weight of the resin were analyzed by elemental analysis. Morphological structure of the synthesized resin was studied by scanning electron microscopy. Thermal properties and stability of the resin was determined by DSC and TGA. The intrinsic viscosity and the viscosity average molecular weight were calculated. Selectivity and binding capacity of the terpolymer resin studied by batch equilibrium method toward $\mathrm{Ni}^{2+}, \mathrm{Co}^{2+}, \mathrm{Cd}^{2+}, \mathrm{Cu}^{2+}, \mathrm{Zn}^{2+}$ and $\mathrm{Cr}^{3+}$ in different $\mathrm{pH}$ and treatment time.

Keywords: Chelating, Terpolymer, Intrinsic viscosity, Biuret, $o$-amino acetophenone.

\section{INTRODUCTION}

The heavy metal ion toxicity has increased strongly because of many industries catalyst contains metal ions. Many techniques have been improved for the pre-concentration and removal of metal ions such as electrodeposition coprecipitation and solid liquid extraction. Chelating resins have been widely used for this purpose to remove the undesired metal ions from aqueous solution. Toxic heavy metal ions are well known in for their toxicity to human health. If the toxic metal ion can be recovered, the energy and material require of the waste water treatment process can be simple. The use of chelating resins for separation and removal metal ions is the method choice due to its highly separation efficiency, high degree of selectivity, high loading capacity [1-3]. Chelating resins are widely used for the treatment of radioactive wastes from nuclear power stations [4,5]. The aromatic compound with substituents like $-\mathrm{OH},-\mathrm{COOH}$ and $-\mathrm{NH}_{2}$ with urea and formaldehyde shows selective ion-exchange properties, thermal resistance properties and coordinating properties [6]. The metal ion uptake increase with increasing mole proportions of the copolymer synthesized from substituted benzoic acid [7]. Salicylic acid-formaldehyde-resorcinol resin has been synthesized and explored its use for removal and separation of heavy metal ions from their binary mixtures [8]. The metal ion-binding properties of terpolymer resins derived from 2,4-dihydroxy acetophenone-biuret-formaldehyde and 2,4-dihydroxy benzaldehyde-oxamide and formaldehyde, respectively have been investigated. In this research, it was synthesized chelating terpolymer resin using an ecofriendly technique and reported for its good binding capacity for $\mathrm{Ba}^{2+}$ and $\mathrm{Zn}^{2+}$ ions [9]. In the present paper, we describe the synthesis of terpolymer resin derived from $o$-aminoacetophenone and biuret with formaldehyde $(o-\mathrm{AABF})$. The resin has been studied for sorption of $\mathrm{Ni}^{2+}, \mathrm{Co}^{2+}$, $\mathrm{Cd}^{2+}, \mathrm{Cu}^{2+}, \mathrm{Zn}^{2+}$ and $\mathrm{Cr}^{3+}$ from aqueous solutions. For this purpose, various factors effecting the chelating such as $\mathrm{pH}$ and treatment time. The regenerating efficiency has been studied by using nitric acid.

$\frac{\text { EXPERIMENTAL }}{\text { o-Amino acetophenne (98 \%, B.D.H), Biuret (99\%, }}$
Fluka) and formaldehyde (37 \%, B.D.H), sodium hydroxide (98\%, B.D.H), hydrochloric acid (99\%, B.D.H), nitric acid (99\%, B.D.H). The stock standard solutions of Ni(II), Cd(II), $\mathrm{Co}(\mathrm{II}), \mathrm{Cu}(\mathrm{II}), \mathrm{Zn}(\mathrm{II})$ and $\mathrm{Cr}(\mathrm{III})$ were prepared by dissolving appropriate amount of metal chlorides in deionized water, N,Ndimethyl formamide (DMF) (Acros, 99.6\%), dimethyl sulfoxide$d_{6}\left(\mathrm{DMSO}-d_{6}\right)$. Elemental analysis is recorded by Microestimation technique Euro EA 3000 Single. FTIR spectrum of synthesized resin carried out in Shimadzu FT-IR 8300 series spectrophotometer. ${ }^{1} \mathrm{H}$ NMR $\left(300 \mathrm{MH}_{\mathrm{Z}}\right.$ ) spectra was recorded using (Ultra Shield, Bruker, Switzerland (DMSO- $d_{6}$ ). UV-visible spectrum of result terpolymer resin was recorded by (Double beam Shimadzu 1800, Japan). Amount of metal ions was estimated by atomic absorption spectrophotometer technique (Emission spectrophotometer Shimadzu (A-A680). 
Thermal analysis of the resin was recorded using DSC (STA PT-1000 linseis model) linseis Company-Germany. Viscometer [ $\mathrm{k}=0.005232]$ Schott-Gerate made in Germany.

Synthesis of $o$-AABF terpolymer resin: The new terpolymer resin ortho-amino acetophenone biuret formaldehyde (o-AABF) was synthesized by the condensation polymerization. In 3 necks, volumetric flask, mixed of $o$-amino acetophenone $(13.5 \mathrm{~g}, 0.1$ $\mathrm{mol}$ ) and biuret $(10.30 \mathrm{~g}, 0.1 \mathrm{~mol})$ with $37 \%$ formaldehyde $(9.0$ $\mathrm{g}, 0.3 \mathrm{~mol}$ ) in $\mathrm{HCl}$ medium at $130^{\circ} \mathrm{C}$ in an oil bath for $5 \mathrm{~h}$. After cooling, red brown solution was formed and next day poured in the ice water to obtain yellowish precipitate then washed with distilled water (Scheme-I). The dried resin was further purified by dissolving in $8 \% \mathrm{NaOH}$ and regenerated in $1: 1(\mathrm{v} / \mathrm{v}) \mathrm{HCl} /$ water [10-12]. This process was repeated twice to separate the pure terpolymer resin and dried vacuum at room temperature.

The purified terpolymer resin was finally grinded and sieved to obtain uniform particles and kept in desiccator over silica gel. The sieved resin was used for further characterization. The FT-IR spectrum shows peaks at $1682 \mathrm{~cm}^{-1}$ of $\left(\mathrm{CO}-\mathrm{CH}_{3}\right), 1599$ $\mathrm{cm}^{-1}$ of the $\left(\mathrm{Ar}-\mathrm{NH}_{2}, 1429 \mathrm{~cm}^{-1}\right.$ of methylene bridges $\left(\mathrm{CH}_{2}\right)$, $1697 \mathrm{~cm}^{-1}$ of $(\mathrm{C}=\mathrm{O})$ in biuret. UV-visible absorption bands in $313 \mathrm{~nm} .{ }^{1} \mathrm{H}$ NMR (400 MHz, DMSO- $d_{6}, \delta \mathrm{ppm}$ ): 10.97-10.92 (s, 1H, C ) , 7.12-5.91 (s, 2H, Cp,d), 5.91-5.32 (s, 2H, $\mathrm{C}_{\mathrm{NH}_{2}},(\mathrm{t}, 1 \mathrm{H}$, $\left.\mathrm{C}_{\mathrm{h}}\right), 3.21-2.64\left(\mathrm{~s}, 6 \mathrm{H}, \mathrm{C}_{\mathrm{e}}\right), 3.51-3.22\left(\mathrm{~s}, 1 \mathrm{H}, \mathrm{C}_{\mathrm{F}}\right)$. Anal. calcd. for $\mathrm{C}_{13} \mathrm{H}_{16} \mathrm{~N}_{4} \mathrm{O}_{3}$ : C $56.51 \%$, H $5.84 \%$, N $20.28 \%, \mathrm{O} 17.37 \%$. Found: C $56.31 \%$, H $6.22 \%$, N $20.26 \%$, O $17.25 \%$.

Preparation of metal solutions: Set of standard metal solutions $\left(\mathrm{Ni}^{2+}, \mathrm{Co}^{2+}, \mathrm{Cd}^{2+}, \mathrm{Cu}^{2+}, \mathrm{Zn}^{2+}\right.$ and $\left.\mathrm{Cr}^{3+}\right)$ were prepared via weighting of certain amount of metal salts $\left(\mathrm{NiCl}_{2} \cdot 6 \mathrm{H}_{2} \mathrm{O}\right.$, $\mathrm{CoCl}_{2} \cdot 6 \mathrm{H}_{2} \mathrm{O}, \mathrm{CdCl}_{2} \cdot 2 \mathrm{H}_{2} \mathrm{O}, \mathrm{CuCl}_{2} \cdot 2 \mathrm{H}_{2} \mathrm{O}, \mathrm{ZnCl}_{2}$ and $\mathrm{CrCl}_{3} \cdot 6 \mathrm{H}_{2} \mathrm{O}$ ), respectively in the deionized water [13] in concentrations 1000 and $100 \mathrm{ppm}$ with different $\mathrm{pH}(2-6)$ by using $(1 \mathrm{M} \mathrm{HCl})$ and $(1 \mathrm{M} \mathrm{NaOH})$ to control the $\mathrm{pH}$.

Chelation efficiency of $\boldsymbol{o}$-AABF: The chelation efficiency of $o$-AABF terpolymer resin was evaluate by batch equilibrium method.

The finely group terpolymer was used to determine its metal ion uptake capacity for specific metal ion such as $\mathrm{Ni}^{2+}$, $\mathrm{Co}^{2+}, \mathrm{Cd}^{2+}, \mathrm{Cu}^{2+}, \mathrm{Zn}^{2+}$ and $\mathrm{Cr}^{3+}$ in the form of their chloride salt aqueous solution, metal ion binding capacity for the terpolymer was studied under two different experimental conditions.

The procedure adopted on removes of metal ions by shaking of the terpolymer $(0.1 \mathrm{~g})$ with $(10 \mathrm{~mL})$ solution having $(100 \mathrm{ppm})$ metal ion concentration for $24 \mathrm{~h}$ at higher $\mathrm{pH}(\mathrm{pH}$ $=6$ ) and $25^{\circ} \mathrm{C}$ where the loading capacity will be in maximum range [14]. The mixture was then filtered off and washing were collected and then the amount of metal ion was estimated by using atomic absorption spectrophotometer

Recovery of metals ions from $o$-AABF: Reactivation of the dry loading resin was carried out by shaking with $10 \mathrm{~mL}$
( $3 \mathrm{M} \mathrm{HNO}_{3}$ ) at different times. After filtration, the metal ions concentrations in the acid solution were calculated via atomic absorption using standard solution curve for the metal in same acid concentration. From recovery metal ions concentration can be calculate the recovery percentage [15].

\section{RESULTS AND DISCUSSION}

Terpolymer resin synthesis: The synthesized resin $(o-$ $\mathrm{AABF}$ ) was dark brown colour. The resin are soluble in polar solvent like dimethyl sulfoxide, N,N-dimethyl formamide and tetrahydrofuran, also soluble in mixture of aqueous sodium, potassium hydroxide solution. The synthesized resin did not show sharpmelting point but undergo decomposition above $500{ }^{\circ} \mathrm{C}$.

The dilute solution of the synthesized terpolymer in concentration of $10^{-5} \mathrm{M}$ in dimethyl sulfoxide exhibited strong UVvisible absorption bands in $313 \mathrm{~nm}$ assignable to the (n- $\left.\pi^{*}\right)$ transitions resulting from the conjugation between the aromatic rings and nitrogen atom (Fig. 1).

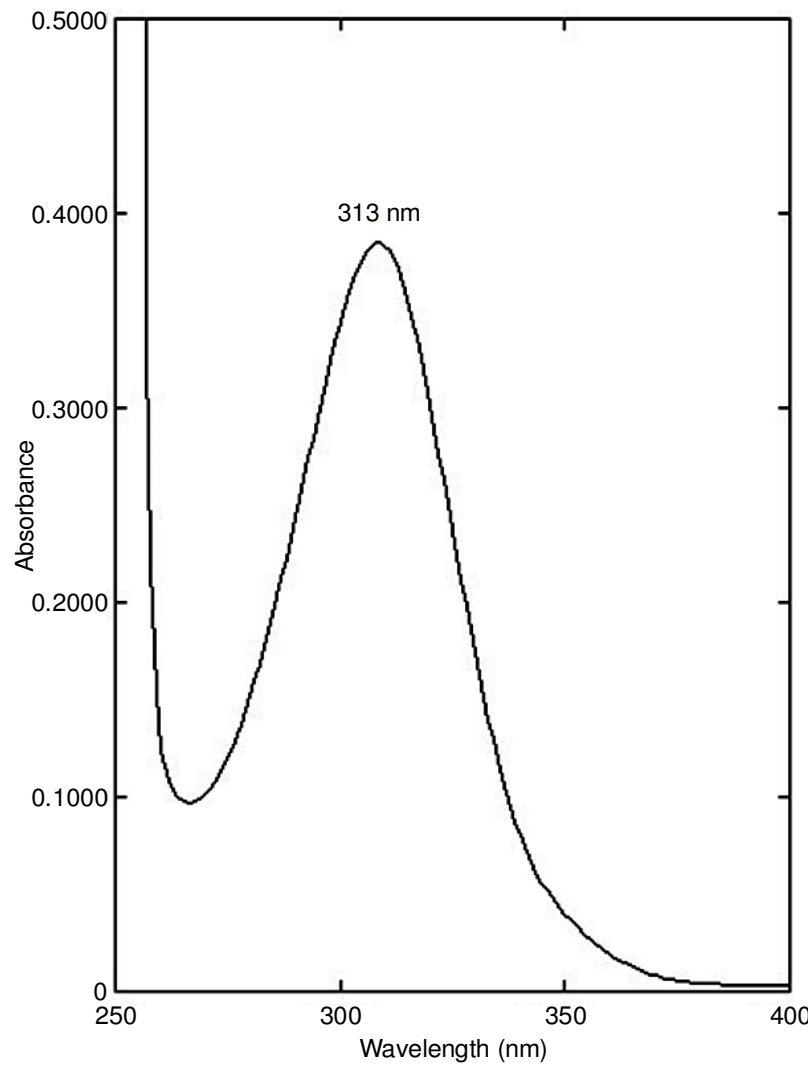

Fig. 1. UV-visible spectrum of $o$-AABF terpolymer

The FT-IR spectrum of $o$-AABF shows the sharp band at $1682 \mathrm{~cm}^{-1}$ due to the stretching vibration of carbonyl group of $\left(\mathrm{CO}-\mathrm{CH}_{3}\right)$ and $-\mathrm{NH}$ stretching vibration of $\mathrm{Ar}-\mathrm{NH}_{2}$ group<smiles>CC(=O)c1ccccc1NC(=O)NC(=O)NCc1cc(C(C)(C)C)cc(C(C)=O)c1N</smiles>

Scheme-I: The synthesis routes of (o-AABF) terpolymer resin 
which is further confirmed by $-\mathrm{NH}$ bending vibration appearing at $1599 \mathrm{~cm}^{-1}$ [16]. A band appea-ring in the region of $1429 \mathrm{~cm}^{-1}$ shows the presence of methylene bridges $\left(\mathrm{CH}_{2}\right)$ in the polymer chain [17]. A sharp and weak peak obtained at $2939 \mathrm{~cm}^{-1}$ indicates the presence of stretching vibration of methylene group $\left(-\mathrm{CH}_{2}\right)$ in the terpolymer chain and the sharp band obtained at $1697 \mathrm{~cm}^{-1}$ due to presence of carbonyl group $(\mathrm{C}=\mathrm{O})$ in biuret in the terpolymer chain (Fig. 2).

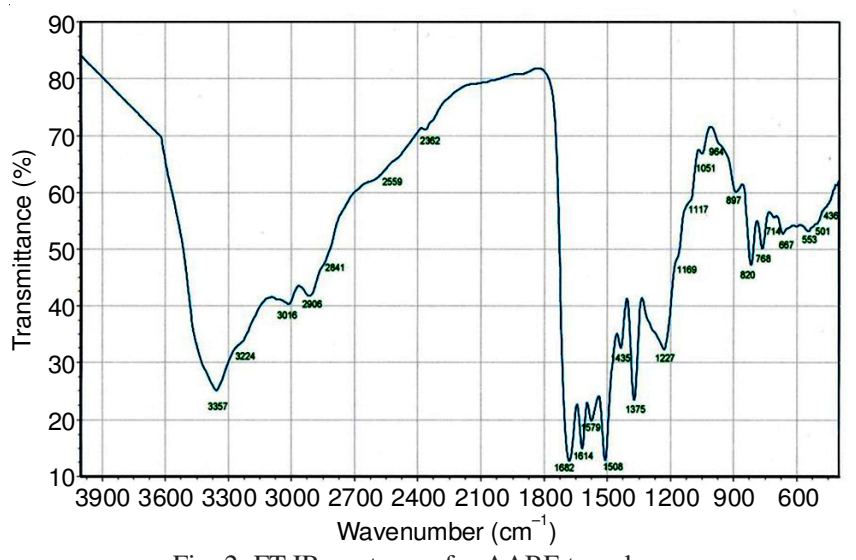

Fig. 2. FT-IRspectrum of $o$-AABF terpolymer

Fig. 3 shows ${ }^{1} \mathrm{H}$ NMR spectrum of $o$-AABF terpolymer resin which explains different patterns of peaks. The signal observed at $(\delta \mathrm{H}=10.97-10.92)$ ppm due to the amide proton (-NH-CO) (g) $[18,19]$. The multiplicity signal (unsymmetrical pattern $)$ in the range of $\left(\delta_{\mathrm{H}}=7.12-5.91\right) \mathrm{ppm}$ attributed to the protons $(b, d)$ of the aromatic ring. The peak in the range $\left(\delta_{\mathrm{H}}=\right.$ 5.91-5.32 ppm) due to the protons of $-\mathrm{NH}-(\mathrm{h})$ and $-\mathrm{NH}_{2}$ groups. The signal in the range of $\left(\delta_{\mathrm{H}}=3.21-2.64 \mathrm{ppm}\right)$ is attributed to protons of methylene bridges $\mathrm{Ar}-\mathrm{CH}_{2}-\mathrm{N}$ (e) and $\mathrm{NH}-\mathrm{CH}_{2}-$ (i) of polymeric chain. The multiply signals appearing at $\left(\delta_{\mathrm{H}}=\right.$ 3.51-3.22 ppm) due to the proton of amide proton linkage (-NH-CO) (f). The sharp peak is attributed to the protons of $-\mathrm{CH}_{2}$ (a) and $\mathrm{CH}_{3}$ (c) groups.

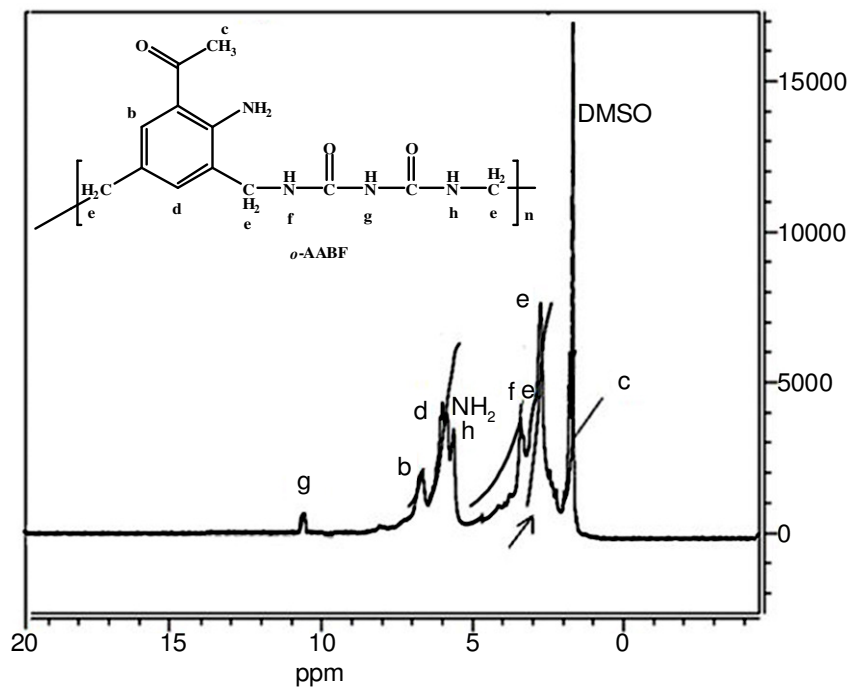

Fig. $3 .{ }^{1} \mathrm{H}$ NMR spectrum of the synthesized $o$-AABF terpolymer

\section{Terpolymer properties}

Thermal analysis: The DSC thermogram of the synthesized terpolymer showed a distinct first glass transition $\left(\mathrm{T}_{\mathrm{g}} 1\right)$ at $348.3{ }^{\circ} \mathrm{C}$ in the scanning rate $20{ }^{\circ} \mathrm{C} / \mathrm{min}$ in nitrogen. After $400^{\circ} \mathrm{C}$ almost completely converted to the corresponding triazole moiety in the chain, which leads to increase chain rigidity of the terpolymer with higher $\mathrm{T}_{\mathrm{g}} 2$ value of $(413.1){ }^{\circ} \mathrm{C}$.

The terpolymer indicated no clear melting endotherm up to the decomposition temperature (Fig. 4). The $o$-ABBF exhibited good thermal stability without significant weight loss up to $400{ }^{\circ} \mathrm{C}$. The $10 \%$ weight-loss temperature was $478^{\circ} \mathrm{C}$. The amount of residue (char yield) was more than $10 \%$ at $560{ }^{\circ} \mathrm{C}$.

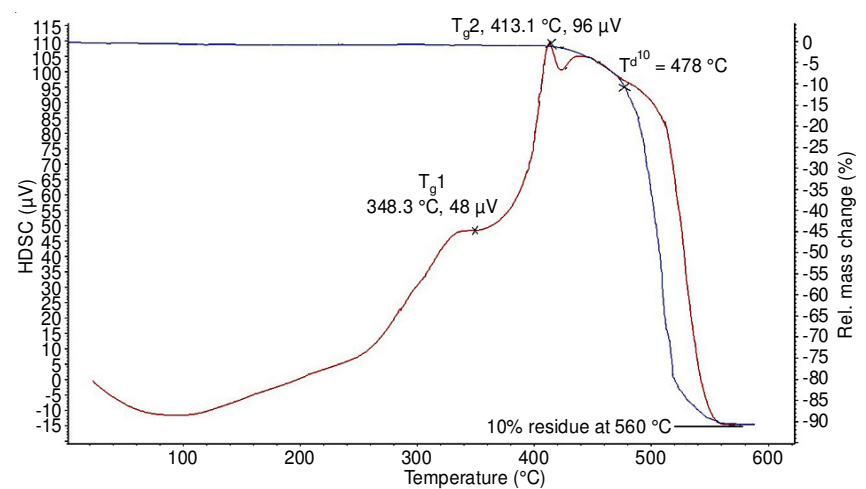

Fig. 4. DSC, TGA thermogram of $o-\mathrm{AABF}$

Analytical chelating resin efficiency: The study of the analytical efficiency of the chelating resins is one of the most important applications in analytical chemistry, where the selective resins for specific elements of the presence of other elements will be based on different active groups in the resin, as per the nature of the atom-giving and this leads to the use of resin as selective separation of different ions to be capture.

There are several techniques used in the study of analytical efficiency of chelating resins. The best of these techniques used for this purpose are atomic absorption spectroscopy which is used in this study. The analytical efficiency of the polymer [ $O$ AABF] towards several ions $\left(\mathrm{Ni}^{2+}, \mathrm{Cd}^{2+}, \mathrm{Co}^{2+}, \mathrm{Cu}^{2+}, \mathrm{Zn}^{2+}, \mathrm{Cr}^{3+}\right)$ have been studied. After shaking $10 \mathrm{~mL}$ of corresponding metal ions, a solution concentration ( $100 \mathrm{ppm})$ with $0.1 \mathrm{~g}$ of polymer for a period of $24 \mathrm{~h}$ has shown a great response ion towards polymer.

Effect of treatment time at maximum capacity to load o-AABF terpolymer: The effect of treatment time on the efficiency of loaded polymer $[o-\mathrm{AABF}]$ to extract metal ions as it was noted that increasing treatment time for the solutions of the studied ions increased loading of the polymer capacity, though the ions reach equilibrium after about $(10 \mathrm{~h})$ and the amount of load capacity becomes a little bit until they reach $24 \mathrm{~h}$ of treatment. Table-1 and Fig. 5 show the effect of treatment time on the load capacity of the polymer $[o-\mathrm{AABF}]$ ions $\left(\left(\mathrm{Ni}^{2+}\right.\right.$, $\mathrm{Cd}^{2+}, \mathrm{Co}^{2+}, \mathrm{Cu}^{2+}, \mathrm{Zn}^{2+}, \mathrm{Cr}^{3+}$ in acidic studied functions.

Effect of acidic function on the analytical efficiency of $\boldsymbol{o}$-AABF: The study showed that the acidic function was with significant effect in the loading capacity of the resin for all studied ions. It has been observed that in general, a higher load capacity of the resin for these ions are at the highest acidic function used in the study of each ion (Fig. 6).

Intrinsic viscosity of $\boldsymbol{o}$-AABF: The viscosity of the resin solution was measured using capillary tube called (Ubbelohde viscometer) by measure the flow time of the solvent used in the composition of the solution polymer $\left(\mathrm{t}^{\mathrm{o}}\right)$ and then measuring 


\begin{tabular}{|c|c|c|c|c|c|c|}
\hline \multicolumn{7}{|c|}{$\begin{array}{c}\text { TABLE-1 } \\
\text { NUMBER OF MILLIGRAMS OF IONS DRAWN BY }(0.1 \mathrm{~g}) \\
\text { OF THE POLYMER [ } o \text {-ABBF] AS A FUNCTION OF } \\
\text { TIME IN DIFFERENT ACIDIC FUNCTION }\end{array}$} \\
\hline \multirow{3}{*}{ Ions } & \multirow{3}{*}{$\mathrm{pH}$} & \multicolumn{5}{|c|}{ Capacity resin mg/g loading } \\
\hline & & \multicolumn{5}{|c|}{ Time (h) } \\
\hline & & $0.5 \mathrm{~h}$ & $1 \mathrm{~h}$ & $3 \mathrm{~h}$ & $10 \mathrm{~h}$ & $24 \mathrm{~h}$ \\
\hline \multirow[t]{3}{*}{$\mathrm{Co}^{2+}$} & 1.0 & 2.0 & 1.6 & 2.4 & 3.2 & 3.9 \\
\hline & 1.3 & 4.0 & 1.9 & 3.1 & 4.3 & 5.6 \\
\hline & 2.5 & 6.0 & 3.7 & 5.1 & 6.5 & 7.3 \\
\hline \multirow[t]{4}{*}{$\mathrm{Ni}^{2+}$} & 1.7 & 2.0 & 2.8 & 3.6 & 4.1 & 4.2 \\
\hline & 2.5 & 4.0 & 3.9 & 5 & 6.2 & 6.5 \\
\hline & 3.2 & 6.0 & 4.5 & 5.9 & 7.0 & 7.7 \\
\hline & 5.1 & 7.0 & 5.0 & 6.9 & 8.1 & 8.3 \\
\hline \multirow[t]{3}{*}{$\mathrm{Cu}^{2+}$} & 2.1 & 2.0 & 3.3 & 3.8 & 3.9 & 4.9 \\
\hline & 3.8 & 4.0 & 4.8 & 5.7 & 6.3 & 6.9 \\
\hline & 5.2 & 6.0 & 6.5 & 6.9 & 7.2 & 7.3 \\
\hline \multirow[t]{3}{*}{$\mathrm{Zn}^{2+}$} & 0.4 & 2.0 & 0.9 & 1.4 & 5.1 & 5.6 \\
\hline & 1.7 & 4.0 & 2.2 & 2.7 & 5.7 & 6.0 \\
\hline & 3.0 & 6.0 & 3.3 & 3.7 & 6.4 & 7.0 \\
\hline \multirow[t]{3}{*}{$\mathrm{Cd}^{2+}$} & 2.1 & 2.0 & 2.8 & 4.4 & 4.7 & 4.9 \\
\hline & 4.0 & 4.0 & 4.8 & 6.0 & 6.2 & 6.4 \\
\hline & 5.0 & 6.0 & 6.1 & 7.0 & 7.3 & 7.4 \\
\hline \multirow[t]{4}{*}{$\mathrm{Cr}^{3+}$} & 0.9 & 2.0 & 1.1 & 1.3 & 2.4 & 2.5 \\
\hline & 2.1 & 4.0 & 3.2 & 4.2 & 4.4 & 4.6 \\
\hline & 5.0 & 6.0 & 5.6 & 6.4 & 6.9 & 7.2 \\
\hline & 8.5 & 7.0 & 9.2 & 9.3 & 9.5 & 9.6 \\
\hline
\end{tabular}

the same solution time (t), across these measurements can calculate viscosity as follows:

\section{Relative viscosity:}

$$
\eta_{\text {rel }}=t / t^{\circ}
$$

Specific viscosity:

$$
\begin{aligned}
\text { Reduced viscosity: } & \eta_{\mathrm{sp}}=\eta_{\text {rel }}-1 \\
\eta_{\text {red }} & =\eta_{\text {sp } / \mathrm{c}}
\end{aligned}
$$

where $\mathrm{c}$ is grams of polymer in $(100 \mathrm{~mL})$ of solvent.

\section{Intrinsic viscosity:}

$$
\eta=\left(\eta_{\text {red }}\right)_{\mathrm{c} 0} \longrightarrow
$$

The fact that the viscosity of an experimental relationship with the molecular weight of the several polymeric systems so Stodnker predicted in 1930 that the viscosity is about equal the molecular weight with a slight modification where it compensates intrinsic viscosity instead of reducing viscosity as shown in equation mark reported by Houwnik [20,21].

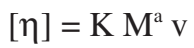

where $\mathrm{a}, \mathrm{K}$ are constants depend on the type of polymer and solvent and solution temperature.

The viscosity of the prepared polymer in this study was measured using viscometer type (Ubbelohde viscometer) in DMSO-as solvent.
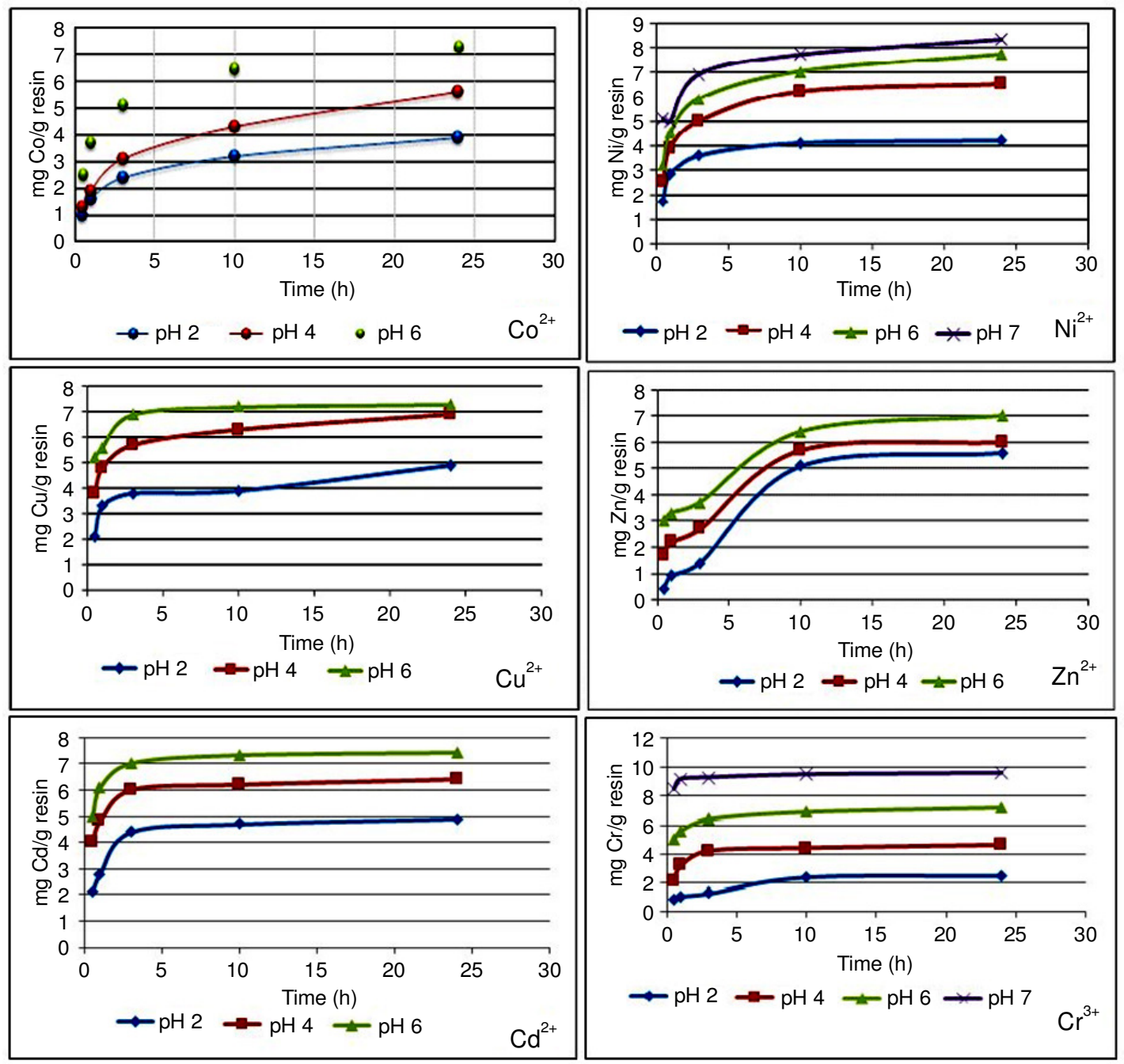

Fig. 5. Number of milligrams ions $\left(\mathrm{Co}^{2+}, \mathrm{Ni}^{2+}, \mathrm{Cu}^{2+}, \mathrm{Zn}^{2+} \mathrm{Cd}^{2+}, \mathrm{Cr}^{3+}\right)$ drawn by $(0.1 \mathrm{~g})$ of the polymer $[o-\mathrm{ABBF}]$ as a function of time in different acidic functions 

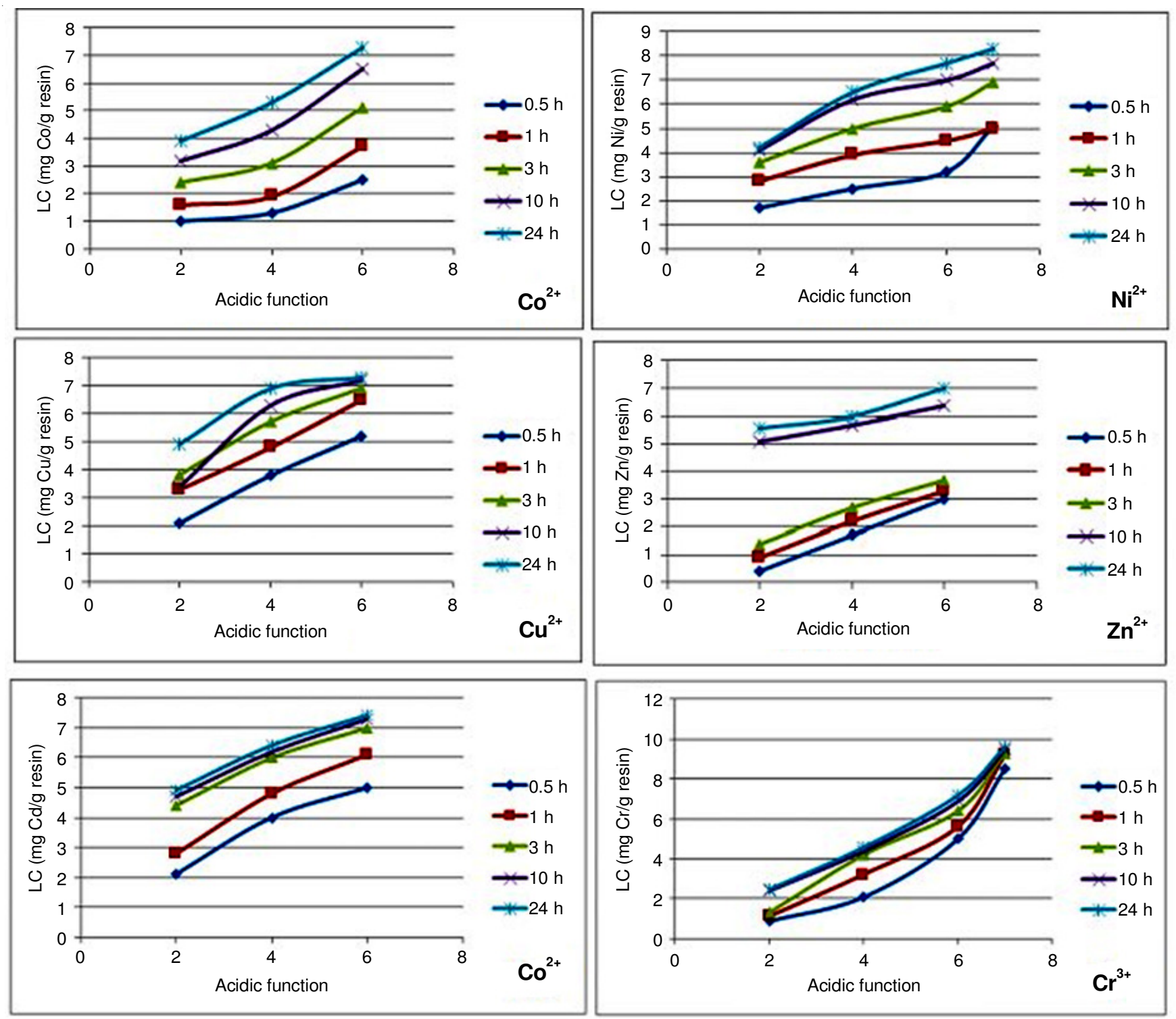

Fig. 6. Effect of acidic function on the loading capacity (LC) of polymer $[o-\mathrm{AABF}]$ of metal ions $\left(\mathrm{Co}^{2+}, \mathrm{N}^{\mathrm{i2}}, \mathrm{Cu}^{2+}, \mathrm{Zn}^{2+} \mathrm{Cd}^{2+}, \mathrm{Cr}^{3+}\right)$ in different treatment times

The relative viscosity is obtained for the resin solution and converted into a relative and reduce viscosity (Table-2) then intrinsic viscosity $(0.563 \mathrm{dL} / \mathrm{g})$ was practically determined via graph between reducing viscosity and concentration of the prepared resin, the intersection of the curve with the y-axis at zero value of concentration as shown in Fig. 7.

\begin{tabular}{ccccc}
\multicolumn{5}{c}{ TABLE-2 } \\
\multicolumn{5}{c}{$\begin{array}{c}\text { THE RELATIVE VISCOSITY, SPECIFIC } \\
\text { VISCOSITY, REDUCED VISCOSITY }\end{array}$} \\
\hline $\mathrm{C}^{1}$ & $\mathrm{~T}^{2}{ }_{\mathrm{sec}}$ & $\eta_{\mathrm{rel}}{ }^{3}$ & $\eta_{\mathrm{sp}}{ }^{4}$ & $\eta_{\mathrm{red}}{ }^{5}$ \\
\hline 0.03 & 113 & 1.027 & 0.027 & 0.900 \\
0.05 & 116 & 1.054 & 0.054 & 1.080 \\
0.07 & 120 & 1.090 & 0.090 & 1.285 \\
0.10 & 128 & 1.164 & 0.164 & 1.640 \\
\hline
\end{tabular}

1: Resin concentration; 2: Solution time (sec.); 3: The relative viscosity (dL/g); 4: Specific viscosity (dL/g); 5: Reduced viscosity $(\mathrm{dL} / \mathrm{g})$

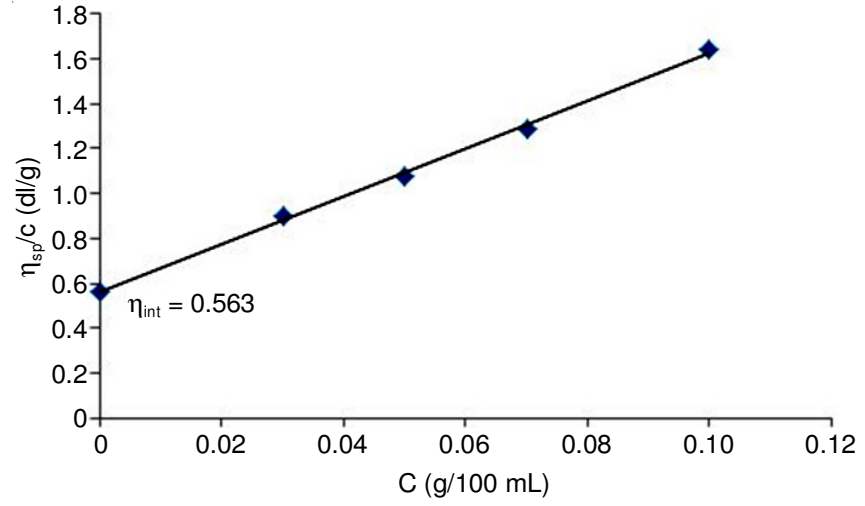

Fig. 7. Intrinsic viscosity of $[o-\mathrm{AABF}]$

\section{Conclusions}

(1) Polymeric resin prepared from $o$-amino acetophenone, biuret and formaldehyde proved the ability to work as chelating 
resin where its extractive efficiency depends on the number of chelating groups or groups capable to form the coordinating links of the group $-\mathrm{NH}_{2}$.

(2) The ability of resin in the extraction of metal ions depends on several factors, including the nature of metals and ions and nature of the link between chelating resin and ions.

(3) The ability of chelating resins composition increased with increasing ionic valance.

(4) In this study, it is found the highest extractive efficiency of the resin is when the values $\mathrm{pH}=8$ where the basic midfield lead to a partial melting of the resin, leading to the difficulty of separating the resin loaded metal ions.

\section{REFERENCES}

1. A.A. Atia, A.M. Donia and K.Z. Elwakeel, React. Funct. Polym., 65 , 267 (2005);

https://doi.org/10.1016/j.reactfunctpolym.2005.07.001.

2. D. Prabhakaran and M.S. Subramanian, Talanta, 59, 1227 (2003); https://doi.org/10.1016/S0039-9140(03)00030-4.

3. S. Nabi, A. Alim, A. Islam and M. Amjad, J. Sep. Sci., 28, 2463 (2005); https://doi.org/10.1002/jssc. 200500170 .

4. R.A. Beauvais and S.D. Alexandratos, React. Funct. Polym., 36, 113 (1998); https://doi.org/10.1016/S1381-5148(98)00016-9.

5. S.A. Patel, B.S. Shah, R.M. Patel and P.M. Patel, Iran. Polym. J., 13, 445 (2004).

6. M. Karunakaran and C. Magesh, Arabian J. Chem., 4, 339 (2011); https://doi.org/10.1016/j.arabjc.2010.06.057.

7. M. Karunakaran and A. Burkanudeen, Orient. J. Chem., 19, 225 (2003).
8. B.A. Shah, A.V. Shah, B.N. Bhandari and R.R. Bhatt, Iran. Polym. J., 16, 173 (2007).

9. R.S. Azarudeen, M.A. Riswan, D. Jeyakumar and A.R. Burkanudeen, Iran. Polym. J., 18, 821 (2009).

10. M.A. Riswan, R.S. Azarudeen, M. Karunakaran and A.R. Burkanudeen, Iran. Polym. J., 19, 635 (2010).

11. W.B. Gurnul, H.D. Junej and L.J. Paliwal, React. Funct. Polym., 50, 95 (2002); https://doi.org/10.1016/S1381-5148(01)00072-4.

12. W.B. Gurnule, P.K. Rahangdale, L.J. Paliwal and R.B. Kharat, Synth. React. Inorg. Met.-Org. Chem., 33, 1187 (2003); https://doi.org/10.1081/SIM-120023486.

13. E. Bowers, Water Quality and Treatment, American Water Association Inc., p. 20 (1971).

14. A. Deratani and B. Sebille, Anal. Chem., 53, 1742 (1981); https://doi.org/10.1021/ac00235a007.

15. T.H. Al-Bayati and M. Sc, Thesis, University of Tikrit, pp. 64-67 (2008).

16. A.R. Burkanudeen, R.S. Azarudeen, M.A.R. Ahamed and W.B. Gurnule, Polym. Bull., 67, 1553 (2011); https://doi.org/10.1007/s00289-011-0497-9.

17. A.I. Vogel, Text Book of Practical Organic Chemistry, Longman Scientific and Technical, London, UK (1989).

18. R.M. Silverstein and F.X. Webster, Spectrometric Identification of Organic Compounds, John Wiley \& Sons, New York (1998).

19. M. Karunakaran, C.T. Vijayakumar, C. Magesh and T. Amudha, Int. J. Eng. Sci. Technol., 1, 3 (2011).

20. J.C. Bevington and T.N. Huckerby, Eur. Polym. J., 42, 1433 (2006); https://doi.org/10.1016/j.eurpolymj.2005.12.011.

21. C. Wu, D. Cao, Y. Cao, Y. Gao and W. Guo, e-Polymers, 8, 123 (2008); https://doi.org/10.1515/epoly.2008.8.1.1416. 